\title{
Perancangan Sistem Pengendalian Persediaan Barang Pada PT. Sukanda Djaya Dengan Menggunakan Metode First Expired First Out
}

\author{
Okta Veza $^{1)}$, Ismail Yusuf Panessai ${ }^{2)}$, Kartini $^{3)}$ \\ 1,2,3Jln. Teuku Umar Lubuk Baja, Telp 0778425391 Fax 458394 Batam 29432 \\ ${ }^{3}$ Program Studi Teknik Informatika, STT Ibnu Sina, Batam \\ e-mail: *1okta@ @stt-ibnusina.ac.id, ${ }^{2}$ ismail.lamintang@yahoo.com, ${ }^{3}$ kartinick04@ gmail.com
}

\begin{abstract}
Abstrak
PT. Sukanda Djaya Batam merupakan perusahaan yang bergerak di bidang distribusi makanan dan minuman. Penelitian ini bertujuan untuk merancang dan mengimplementasikan sistem pengendalian persediaan barang pada PT. Sukanda Djaya yang belum pernah digunakan sehinnga admin dan team di gudang memerlukan waktu untuk mengetahui barang-barang persediaan yang sudah expired di gudang yang dilakukan secara manual. Sasaran penelitian ini yaitu admin yang bertugas untuk mengelola seluruh aktifitas keluar masuk barang pada PT. Sukanda Djaya Batam menggunakan sistem pengendalian persediaan barang agar proses pencatatan/input barang persediaan terorganisir dengan baik sesuai dengan metode first expired first in dengan sistem yang akan diimplementasikan. Output yang dihasilkan terdiri dari proses stock barang dan kondisi barang sampai pembuatan laporan kondisi barang yang bertujuan agar perusahaan dapat tercapai dengan efektif dan efisien dalam pengelolaan barang tersebut.
\end{abstract}

Kata Kunci-First Expired First Out, Persediaan Barang, PT Sukanda Djaya.

\section{Abstract}

PT. Sukanda Djaya Batam is a company engaged in the distribution of food and beverages. This study aims to design and implement inventory control system at PT. Sukanda Djaya that has never been used sehinnga admin and team in the warehouse takes time to find out the inventory items that have been expired in the warehouse is done manually. The target of this research is admin administered to manage all activities in and out of goods at PT. Sukanda Djaya Batam uses inventory control system so that the process of recording / input of inventory goods is well organized in accordance with the first expired first method with the system to be implemented. The resulting output consists of the process of stock goods and condition of goods until the manufacture of goods condition report which aims for the company can be achieved effectively and efficiently in the management of the goods.

Keywords — First Expired First Out, Inventory, PT Sukanda Djaya

\section{PENDAHULUAN}

PT. Sukanda Djaya merupakan salah satu perusahaan distribusi makanan dan minuman di Indonesia yang berdiri tahun 1978. Dengan 16 kantor cabang distribusi di seluruh Indonesia, dan salah satunya beroperasi di kota Batam. PT. Sukanda Djaya memiliki berbagai macam produk makanan dan minuman. yang salah satunya memiliki masa kedaluwarsa kurang dari tiga bulan. Persediaan mencakup bahan-bahan, bagian yang disediakan, serta barang-barang jadi atau produk 
yang disediakan untuk memenuhi permintaan dari pelanggan setiap waktu (Rangkuti, 2008). Persediaan memiliki fungsi penting yang dapat meningkatkan efisiensi operasional suatu perusahaan. Dengan adanya persediaan, maka proses produksi tidak terhambat oleh kekurangan ketersediaan pada stok barang.

Kualitas barang merupakan salah satu aspek penting dalam suatu managemen. Kerusakan kedaluwarsa pada barang dapat menimbulkan penolakan barang dari pelanggan, sehingga menimbulkan dampak yang merugikan dan dapat mempengaruhi total biaya produksi. Masalah yang sering dihadapi perusahaan ini adalah sering terdapat barang yang kedaluwarsa akibat penumpukan barang, serta membutuhkan waktu yang cukup lama dalam mengindentifikasi masa kedaluwarsa suatu barang, agar menghindari terjadinya penolakan barang dari pihak pelanggan, maka dibutuhkan sistem yang lebih terstruktur yang dapat digunakan untuk mengontrol masa aktif unit kedaluwarsa. Sehingga dapat menunjang efisiensi proses pengolahan data produk dengan metode First Expired First Out.

\section{METODE PENELITIAN}

\subsection{Sumber Data}

Adapun sumber data yang dikumpulkan dari penelitian ini meliputi data primer dan data sekunder.

\subsubsection{Data Primer}

Data Primer adalah data yang diperoleh secara langsung dari sumbernya, yaitu dengan melakukan observasi terhadap informasi yang dijadikan tempat penelitian tugas akhir ini, data primer yang didapat adalah:

1. Koordinat lokasi SPBU yang ada di Kota Batam

2. Data rute yang dapat dilalui untuk menuju SPBU di Kota Batam

\subsubsection{Data Sekunder}

Data Sekunder adalah data yang diperoleh dari buku-buku, jurnal, dan dokumendokumen. Jurnal penelitian terdahulu yang telah ada atau yang tersedia sebelumnya. Adapun data sekunder adalah sebagai berikut :

1. Gambaran Umum DPC Hiswana Migas Kepulauan Riau

2. Data - Data Terkait SPBU di Kota Batam

\subsection{Metode Pengolahan Data}

Metode pengolahan data yang digunakan dalam penelitian ini adalah sebagai berikut :

1. Analisa Sistem yang akan dibuat

2. Data Flow Diagram

3. Perancangan Database

4. Perancangan Input

5. Perancangan Output

6. Pengujian dan perbaikan sistem

7. Implementasi

\subsection{Pengumpulan Data}

\section{HASIL DAN PEMBAHASAN}

Berdasarkan observasi yang penulis lakukan Pada PT Sukanda Djaya. Diperoleh data yang akan diolah untuk sistem informasi yang akan dirancang. Data tersebut dapat dilihat pada table 4.1:

Tabel 1. Data 


\begin{tabular}{|c|l|}
\hline No & \multicolumn{1}{|c|}{ Nama Data } \\
\hline 1 & Data Profile PT Sukanda Djaya (Lampiran 1) \\
\hline 2 & Data Barang 2017 (Lampiran 2) \\
\hline 3 & Data Petugas (Lampiran 3) \\
\hline
\end{tabular}

\subsection{Analisa Sistem}

\subsubsection{Aliran Sistem Informasi}

Data yang penulis kumpulkan, selanjutnya akan diolah agar bisa digunakan untuk sistem baru yang telah direncanakan, dan digambarkan dengan tahapan aliran sistem informasi yang berjalan, dan memberikan usulan pada aliran sistem informasi yang baru.

1. Aliran Sistem Informasi Lama (ASI Lama).

Pada Aliran Sistem Informasi Lama (ASI Lama) semua kegiatan yang berhubungan dengan data persediaan barang di PT Sukanda Djaya masih dilakukan secara manual. Penggambaran dari Aliran Sistem Informasi Lama (ASI Lama) dapat dilihat pada gambar 1:

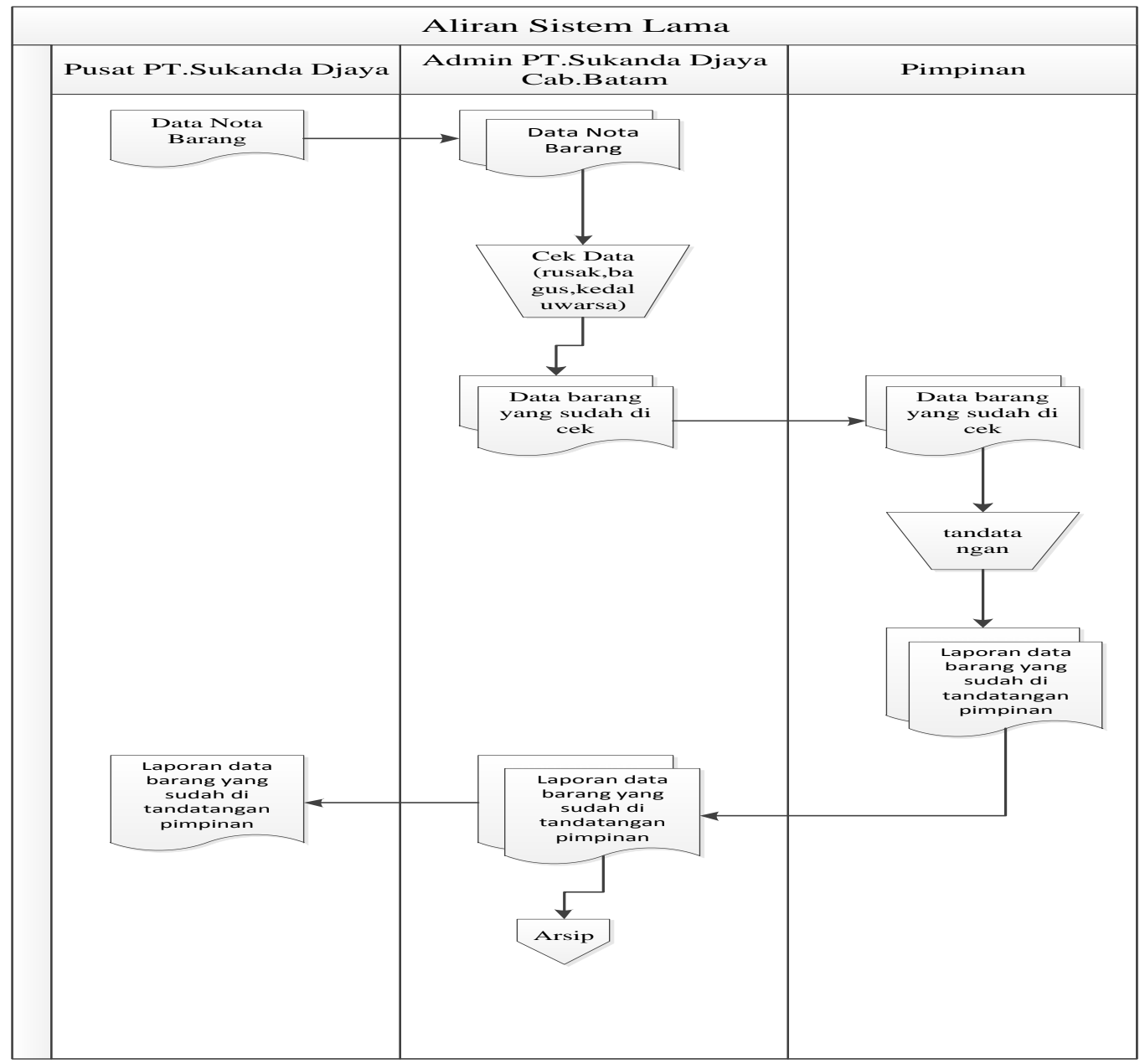

Gambar 1. Aliran Sistem Informasi Lama (ASI Lama).

Aliran sistem informasi yang sedang berjalan di PT Sukanda Djaya, dengan proses sebagai berikut:

1. Data nota barang dikirim ke Cabang PT. Sukanda Djaya Batam.

2. Data nota barang diterima oleh admin PT. Sukanda Djaya Batam.

3. Admin melakukan pemilahan antara barang bagus dan barang rusak serta barang kedaluwarsa).

4. Laporan data barang yang sudah di cek.

5. Laporan barang yang sudah di cek, diserahkan kepada pimpinan. 
6. Laporan barang ditandatangani pimpinan

7. Laporan barang yang sudah ditandatangani pimpinan, diarsip oleh admin.

8. Laporan barang yang sudah ditandatangani pimpinan, dikirim kembali ke pusat PT. Sukanda Djaya.

2. Aliran Sistem Informasi Baru (ASI Baru)

Aliran sistem informasi yang baru adalah merupakan perbaikan dari sistem yang lama, dimana sistem yang pada awalnya manual atau semi komputer menjadi terkomputerisasi atau berbasis database. Antara aliran sistem informasi lama dan aliran sistem informasi baru tidak begitu banyak terjadi perubahan. Perubahan terjadi hanya pada proses penyimpanan dan pengolahan data.

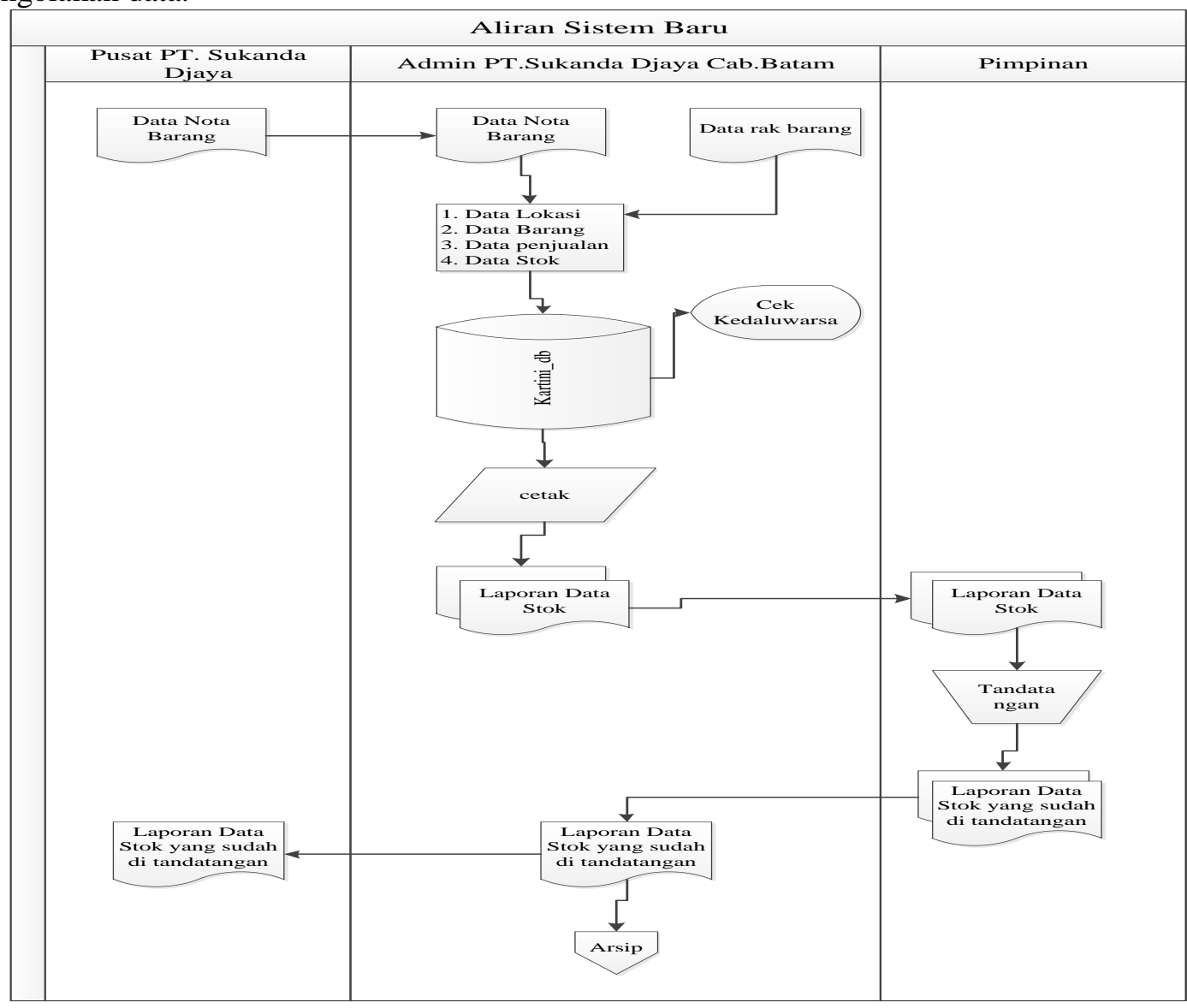

Gambar 2. Aliran Sistem Informasi Baru (ASI Baru).

Dari gambar di atas terlihat bahwa tidak banyak perbedaan antara Alur Sistem Informasi Lama dengan Alur Sistem Informasi Baru. Berikut adalah penjelasan dari gambar untuk Alur Sistem Informasi Baru.

\subsection{Perancangan Sistem}

Perancangan sistem merupakan tahapan selanjutnya setelah menganalisa sistem yang ada, serta mendapatkan gambaran dengan jelas tentang apa yang akan dikerjakan. Untuk mencapai harapan pembuatan sistem, rancangan sistem ini akan digambarkan menggunakan data flow diagram, rancangan database dan relasi database.

\subsubsection{Data Flow Diagram}

Oktober 2018 | Vol. 3 | No. 2 | ISSN : 2541-2647 
Pada tahap ini peneliti akan menunjukan usulan alur proses sistem yang akan dibuat dengan menunjukan fungsi-fungsi sistem kepada user secara logika dengan menggunakan tools DFD (Data Flow Diagram), dan dapat dilihat pada gambar 3, 4, dan 5:

1. Diagram Konteks

Alur proses dari pengembangan aplikasi ini dapat digambarkan dalam suatu Context diagram sebagai berikut:

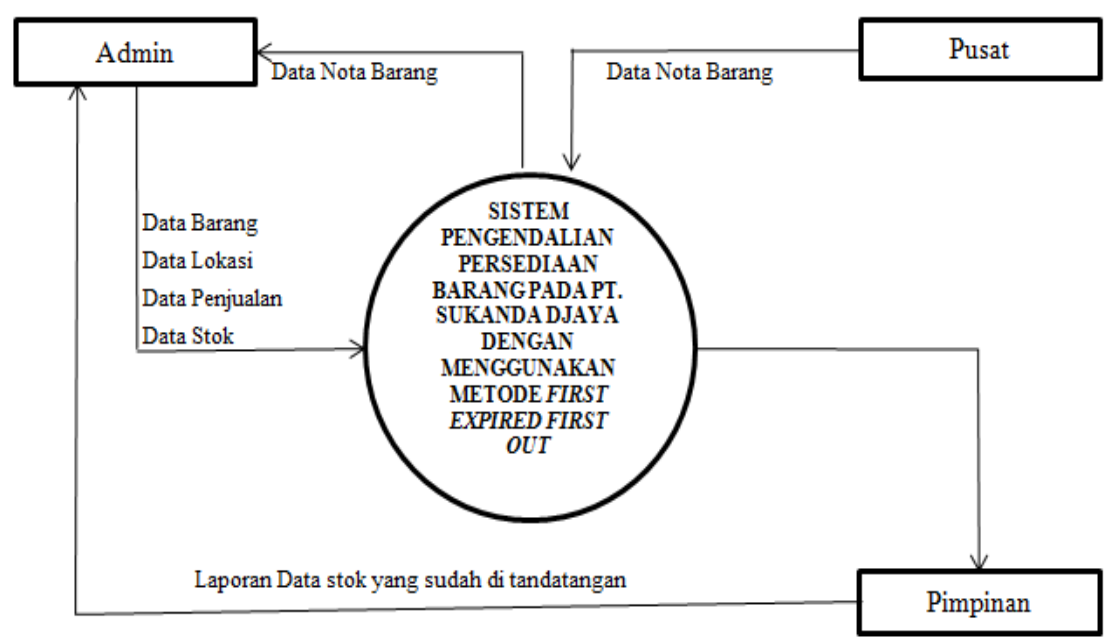

Gambar 3. Diagram Konteks.

2. DFD Level 0

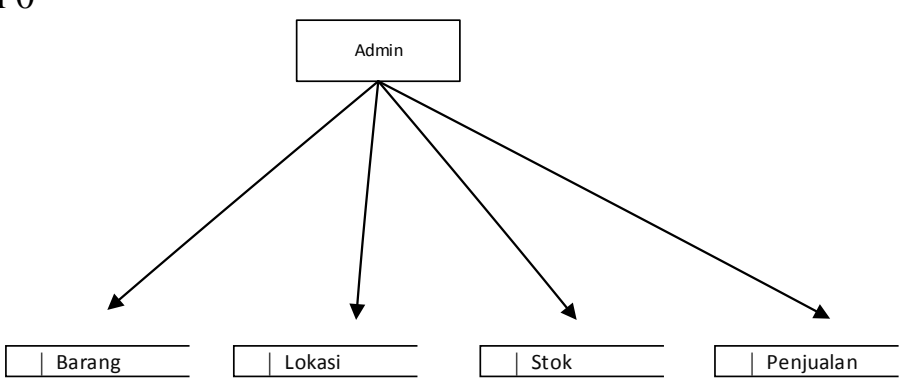

Gambar 4. DFD Level 0.

3. Diagram Rinci Proses 1

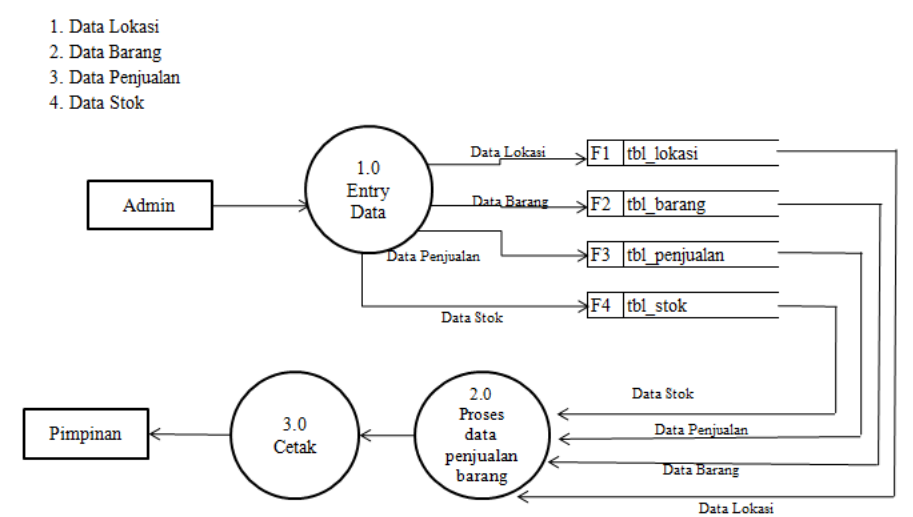

\subsection{Implementasi}

Gambar 5. Diagram Rinci Proses 1. 
Berdasarkan perancangan sistem yang telah dibuat sebelumnya, pada implementasi ini akan menyertakan gambar dari aplikasiPerancangan Sistem Pengendalian Persediaan Barang Pada PT Sukanda Djaya Dengan Menggunakan Metode First Expired First Outberbasis web yang telah dijalankan pada Web Browser yaitu Mozilla Firefox.

Ada dua sisi tampilan yang akan disajikan yaitu tampilan distributor dan tampilan suplier.suplier mampu menambah, mengubah dan menghapus data user serta menambah data barang. Berikut langkah-langkah untuk melihat website yang telah dibuat.

1. Pastikan web server telah berjalan dan jika belum maka pilih start pada apache dan MySql, disini penulis menggunakan aplikasi XAMPP dan untuk tampilannya dapat dilihat pada gambar $6 .:$

\begin{tabular}{|l|l|l|l|l|l|}
\hline MAMPP Control Panel v3.2.2 [ Compiled: Nov 12th 2015] \\
Modules
\end{tabular}

Gambar 6. Tampilan Control Panel Xampp.

2. Selanjutnya buka media browser, disini penulis menggunakan mozila firefox lalu ketikan pada alamat url http://localhost/kartini, maka akan muncul tampilan login seperti pada gambar 7.:

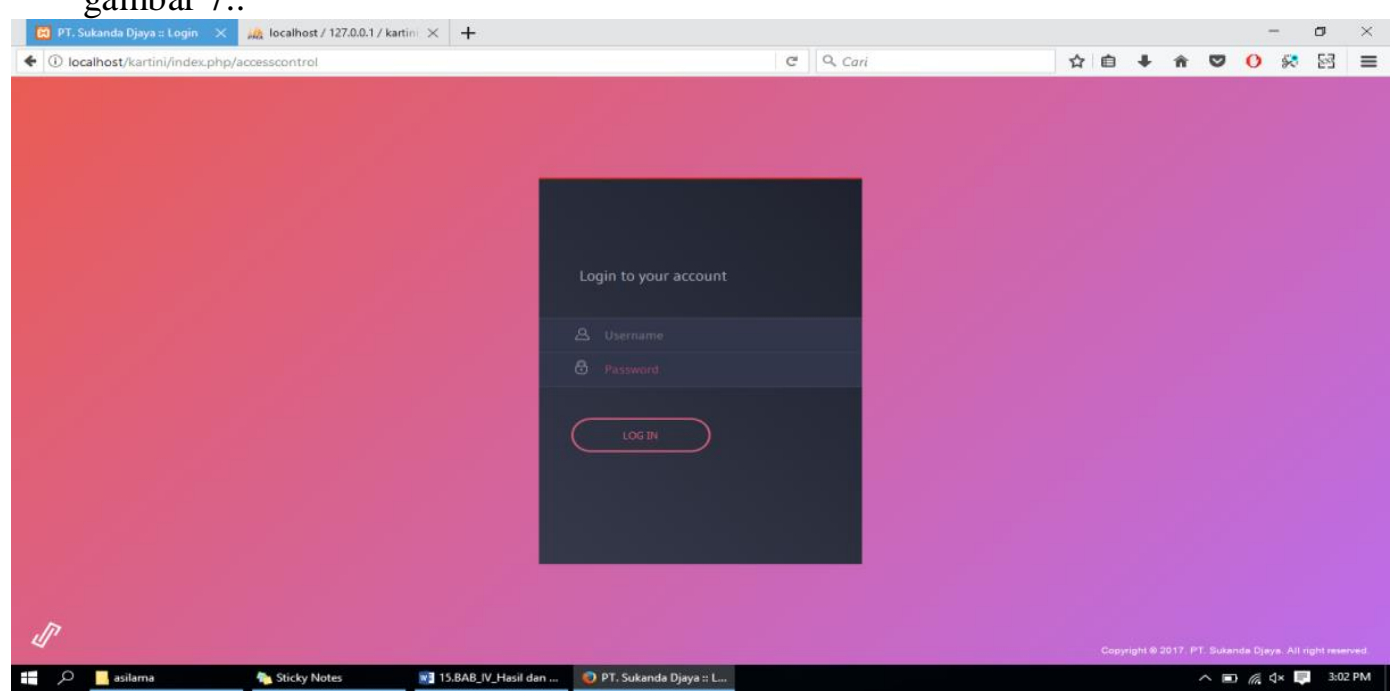

Gambar 7. Tampilan Login.

3. Terdapat dua tampilan utama yakni tampilan admin dan user. 
4. Pada tampilan utama web, terdapat tampilan login yang berfungsi sebagai keamanan untuk login ke halaman admin, untuk lebih ditailnya tampilan admin dan tampilan customers akan dipaparkan sebagai berikut:

Tampilan Aplikasi.

Pada tampilan admin terdapat fom tambah barang, tambah lokasi, tambah persediaan barang, penjualan serta penambahan data akses. Untuk detailnya dapat dilihat pada gambar 8 sampai dengan 13:

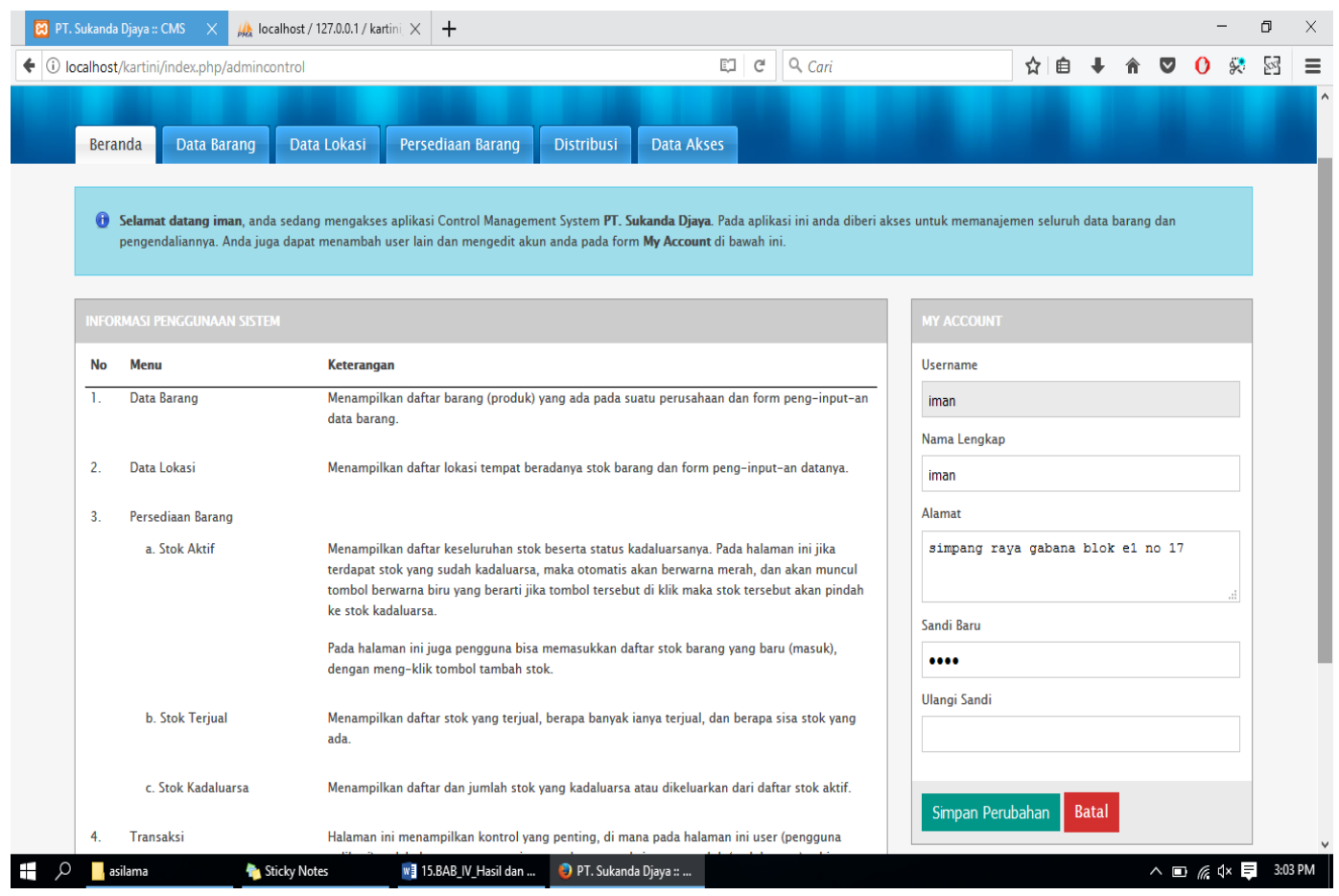

Gambar 8. Tampilan Home.

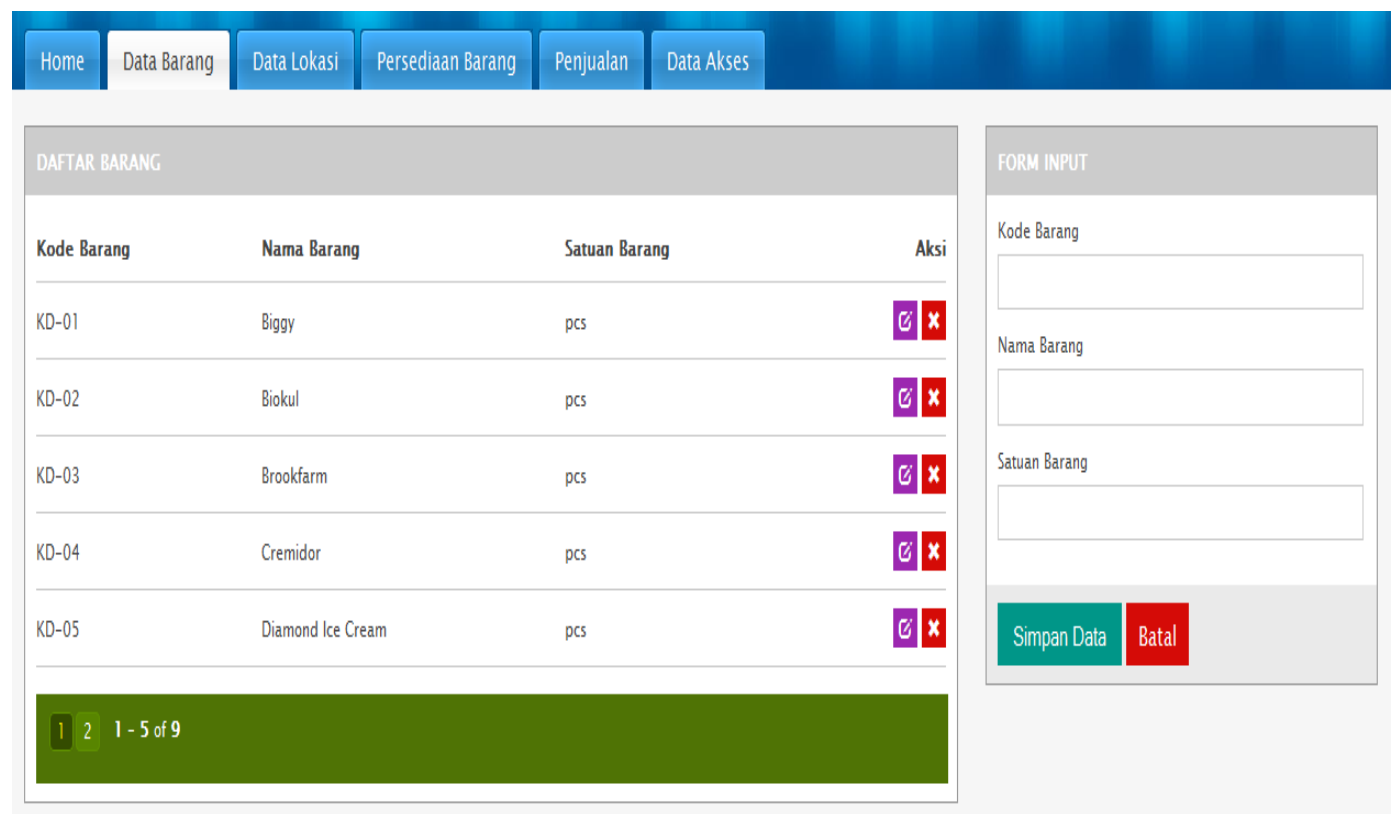

Gambar 9. Tampilan Data Barang.

tampilan menu pada gambar 11 Data Barang terdapat form tambah barang serta tombol untuk mengubah dan menghapus data barang yang ada. 


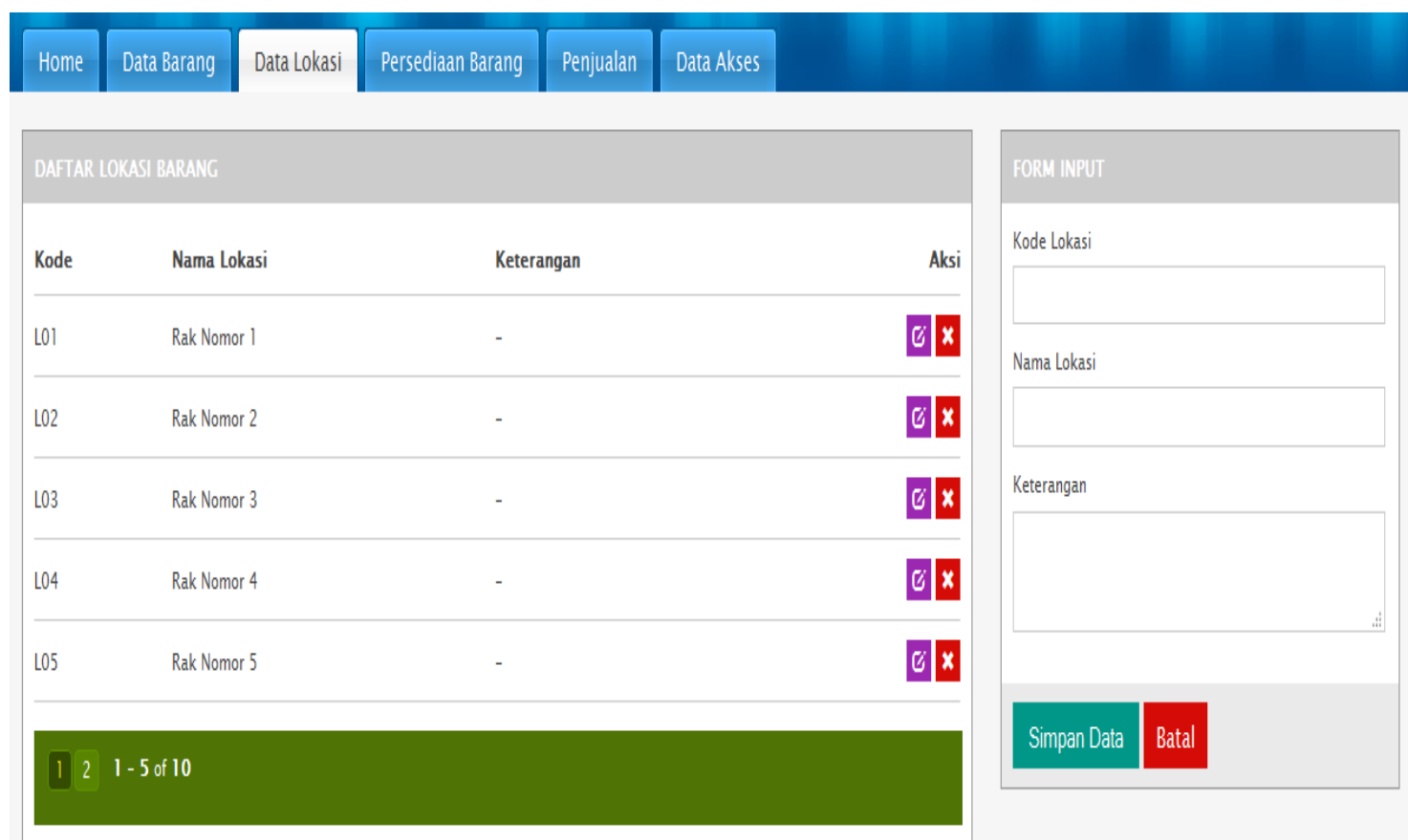

Gambar 10. Tampilan Data Lokasi. disimpan.

Data lokasi bertujuan untuk menambah, mengubah dan menghapus lokasi letak barang
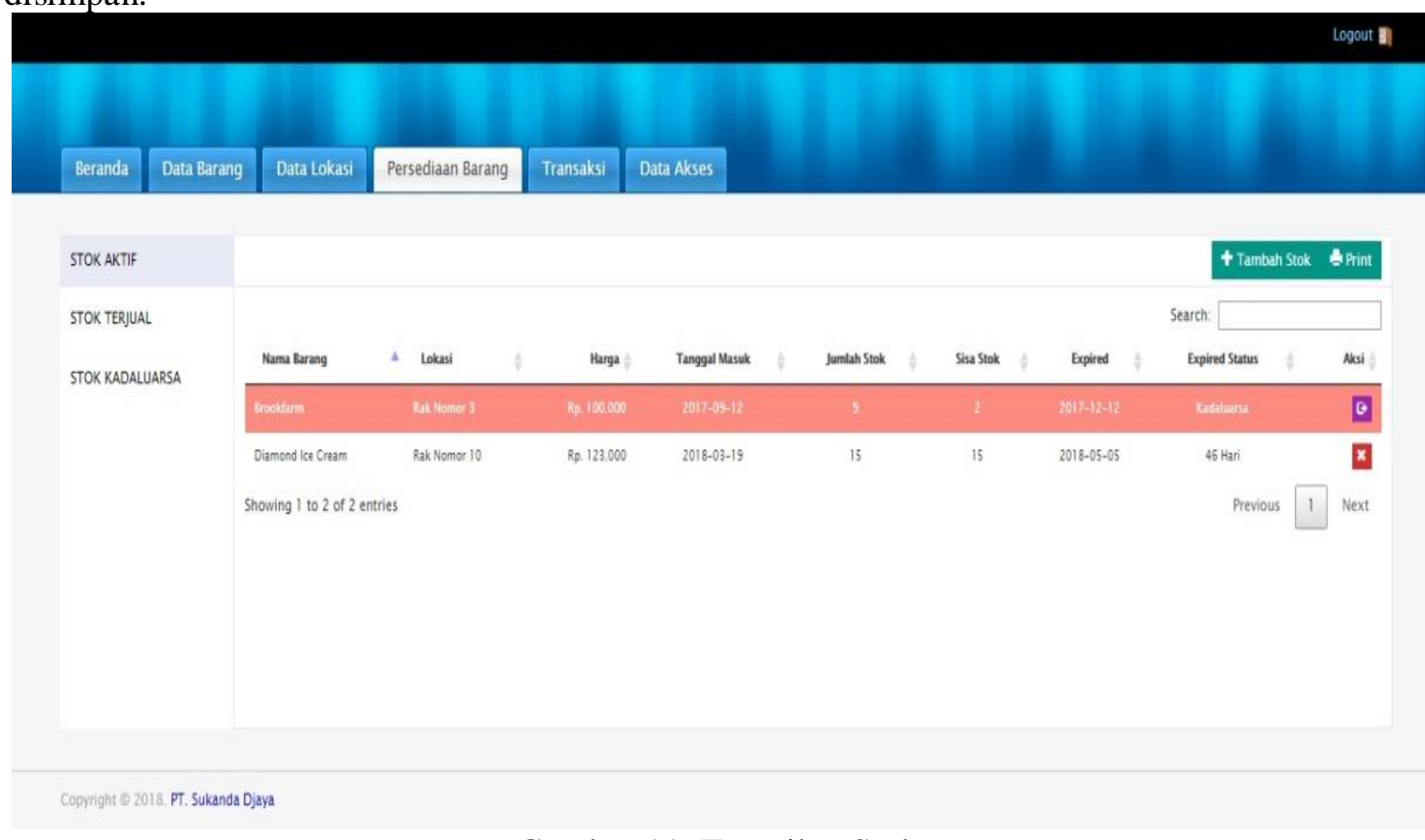

Gambar 11. Tampilan Stok

Pada halaman persediaan barang terdapat menu stok aktif, stok terjual dan stok kedaluwarsa. 


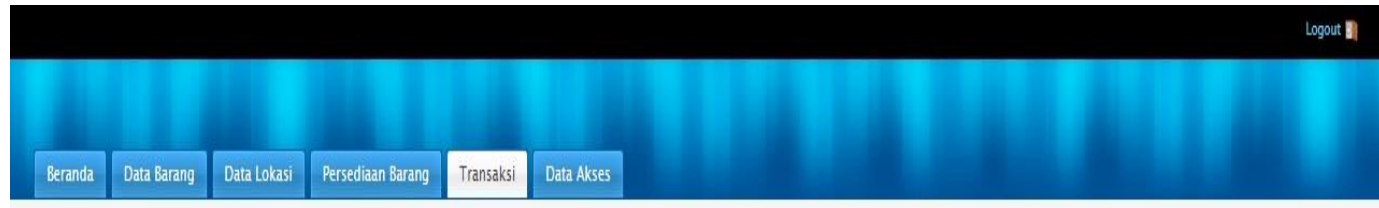

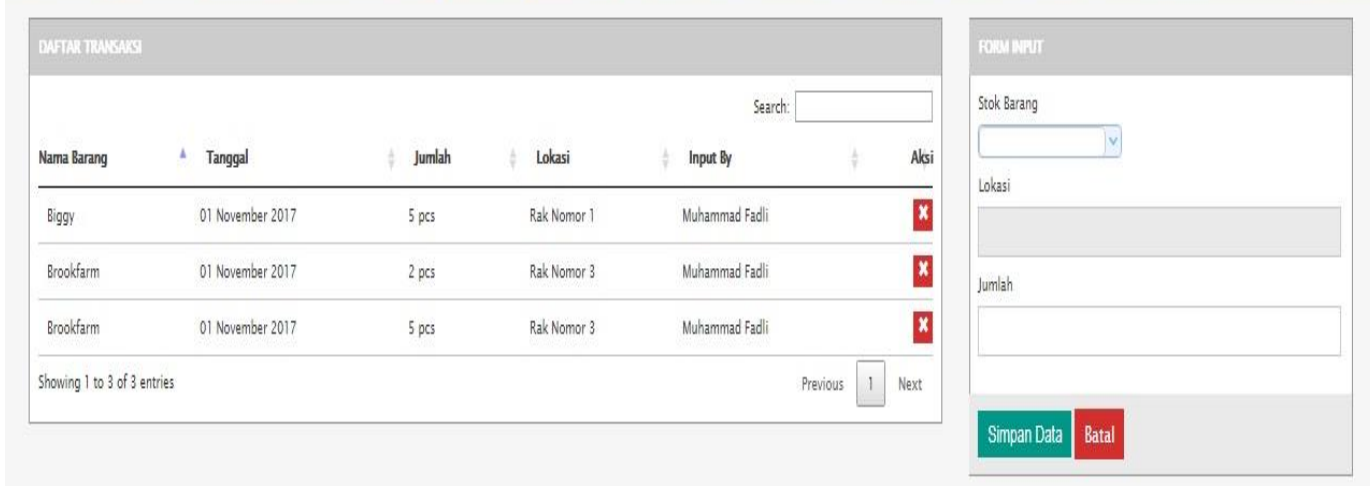

Copyight 8 2018. P. Sukanda Djaya

Gambar 12. Tampilan Penjualan

Pada menu penjualan akan menampilkan data form transaksi penjualan

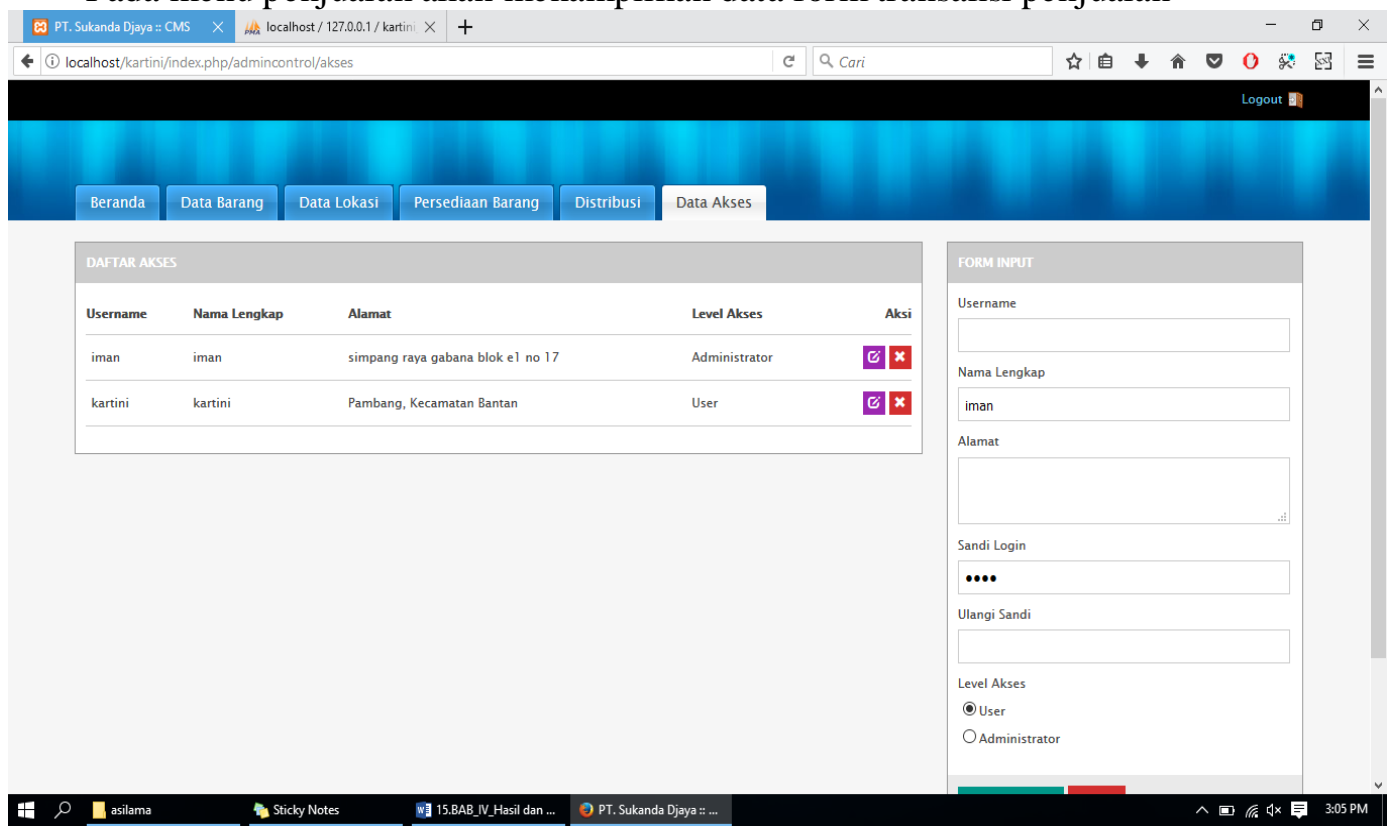

Gambar 13. Tampilan Data Akses

Fom data user berfungsi untuk menambah data user admin yakni data user dan data admin.

\subsection{Prinsip Kerja Sistem Yang Dibuat}

Perancangan Sistem PengendalianPersediaan Barang Pada PT Sukanda Djaya Dengan Menggunakan Metode First Expired First Out ini di buat dengan prinsip kerja sebagai berikut:

1. Terdapat dua tampilan aplikasi yakni:

1. Super admin yang dapat menambah login admin, menambah produk, menambah barang serta mengubah status barang ke kedaluwarsa, terjual atau aktif.

2. Admin hanya dapat menambah data barang serta mendistribusikannya. 
2. Barang yang tersedia di aplikasi ini hanya meliputi barang yang tersedia di PT. Sukanda Djaya.

3. Aplikasi ini masih terletak di localhost karna belum dilakukan hosting.

\section{DAFTAR PUSTAKA}

Abdurahman, H., \& Riswaya A.R. (2014). Aplikasi Pinjaman Pembayaran Secara Kredit pada Bank Yudha Bhakti. Jurnal Computech \& Bisnis Vol. 8 No. 2 Desember 2014.

Apriyanti, L.F. (2013). Sistem Informasi Pengolahan Data Gereja Pada Gpib Galilea Palabuhanratu. Fakultas Teknik Dan Ilmu Komputer Universitas Komputer Indonesia. Skripsi Universitas Komputer Indonesia 2013.

Gumelar, C., \& Udjulawa, D. (2014). Sistem Informasi Transportasi Di Palembang Berbasis Android pada PT. Sarana Pembangunan Palembang Jaya. STMIK GI MDP Palembang 2014.

Iswandy, E. (2015). Sistem Penunjang Keputusan Untuk Menentukan Penerimaan Dana Santunan Sosial Anak Nagari Dan Penyalurannya Bagi Mahasiswa Dan Pelajar Kurang Mampu Di Kenagarian Barung-Barung Balantai Timur. Jurnal TEKNOIF Vol. 3 No. 2 Oktober 2015.

Lamrisna. (2016). Sistem Informasi Pengolahan Warehouse Produk Sarung Tangan Lateks Pada Pt. Intan Hevea Industry Menggunakan Metode Fefo (First Expired First Out). Skripsi Universitas Potensi Utama 2016.

Masykur, F., \& Atmaja, I.M.P. (2015). Sistem Administrasi Pengelolaan Arsip Surat Masuk Dan Surat Keluar Berbasis Web. Universitas Muhammadiyah Ponorogo. IJNS Vol.4 No.3 Juli 2015.

Muhbib, A.H. (2013). Implementasi Desktop Sistem Inventasi Pada Hudi Motor Karangrayung Grobogan. Universitas Dian Nuswantoro 2013.

Nuh, M. (2012). Pembangunan Sistem Informasi Presensi Siswa Pada Sekolah Menegah Atas (Sma) Negeri 1 Rembang Berbasis Finger Print. Journal Speed Vol.4 No.4 2012.

Purwaningtias, F. (2016). Sistem Informasi Apotek Menggunakan Metode First Expiry First Out (FEFO) Pada Rumah Sakit Muhammadiyah Palembang. Jurnal ISSN, 2407-1730.

Rachmayati, P. O. (2014). Sistem Informasi Perencanaan Dan Pengendalian Persediaan Bahan Makanan Pada Instalasi Gizi Rsud Kota Bandung. Skripsi Universitas Komputer Indonesia 2014.

Saputra, R. (2015). Desain Sistem Informasi Order Photo Pada Creative Studio Photo Dengan Menggunakan Bahasa Pemrograman Visual Basic.Net 2010. Jurnal Momentum Vol.17 No.2 Agustus 2015.

Tamodia, W. (2013). Evaluasi Penerapan Sistem Pengendalian Intern Untuk Persediaan Barang Dagangan Pada PT. Laris Manis Utama Cabang Manado. Fakultas Ekonomi. Jurnal EMBA Vol.1 No.3 Juni 2013 Hal 20-29. 
Trisnawan, A.D., \& Amron. (2014). Pengaruh Kualitas Produk, Harga, Promosi dan Distribusi Terhadap Loyalitas Konsumen Handphone Samsung Di Semarang. Jurnal Fakultas Ekonomi Dan Bisnis Universitas Dian 2014.

Verawati, V.L., \& Oetomo, H.W. (2014). Pengaruh Perputaran Modal Kerja, Perputaran Piutang, Dan Perputaran Persediaan Terhadap Profitabilitas Perusahaan Tekstil. Sekolah Tinggi Ilmu Ekonomi Indonesia. Jurnal Ilmu \& Riset Manajemen Vol.3 No.9 2014.

Vironica, A., \& Sukadi (2013). Rancang Bangun Aplikasi Pengelolaan Surat Masuk Dan Surat Keluar Pada Sekolah Menengah Pertama Negeri 2 Nawangan. Journal Speed Vol. 5 No. 42013

Veza, O. (2017). Perancangan Sistem Informasi Inventory Data Barang Pada Pt. Andalas Berlian Motors (Studi Kasus: PT Andalas Berlian Motors Bukit Tinggi). Jurnal Teknik Ibnu Sina JT-IBSI, 2(2).

Wahyuningsih, S.D. (2014). Efektivitas Dan Efisiensi Proses Produksi Melalui Optimalisasi Sistem Pengendalian Manajemen. Jurnal Kompilek Vol.6 No.2 Desember 2014.

Zefriyenni., \& Santoso, B. (2015). Sistem Informasi Penjualan Dan Pengendalian Persediaan Barang Menggunakan Metode Economic Order Quantity (Eoq) Menggunakan Bahasa Pemrograman Java Dan Database Mysql Pada Toko Kansa Elpiji. Jurnal KomTekInfo Fakultas Ilmu komputer Universitas Putra Indonesia YPTK Padang Vol.2 No.2 Desember 2015. 